\title{
Novel transparent nanocomposite films based on chitosan and bacterial cellulose
}

\author{
Susana C. M. Fernandes, ${ }^{a, b}$ Lúcia Oliveira, ${ }^{a}$ Carmen S. R. Freire, ${ }^{* a}$ Armando J. D. Silvestre, ${ }^{a}$ \\ Carlos Pascoal Neto, ${ }^{a}$ Alessandro Gandini ${ }^{a}$ and Jacques Desbriéres ${ }^{b}$
}

\author{
Received 5th May 2009, Accepted 9th September 2009 \\ First published as an Advance Article on the web 22nd October 2009 \\ DOI: 10.1039/b919112g
}

New nanocomposite films based on different chitosan matrices (two chitosans with different DPs and one water soluble derivative) and bacterial cellulose were prepared by a fully green procedure by casting a water based suspension of chitosan and bacterial cellulose nanofibrils. The films were characterized by several techniques, namely SEM, AFM, X-ray diffraction, TGA, tensile assays and visible spectroscopy. They were highly transparent, flexible and displayed better mechanical properties than the corresponding unfilled chitosan films. These new renewable nanocomposite materials also presented reasonable thermal stability and low $\mathrm{O}_{2}$ permeability.

\section{Introduction}

Over the past few years, a renewed and increasing interest on the exploitation of biomass resources for the development of new materials has been observed. This global tendency appears as a natural response for the predictable scarcity of fossil resources and also to the environmental problems associated with their continuous use during the last century. Polysaccharides, in particular cellulose, but also chitin and its derivative chitosan, as well as starch, are of increasing interest as new functional polymeric renewable materials because of their abundance and specific properties. ${ }^{1}$

Chitosan exhibits unique physicochemical properties like biocompatibility, antimicrobial activity, biodegradability and excellent film-forming ability, which have attracted scientific and industrial interest in fields such as biotechnology, pharmaceutics, biomedicine, packaging, wastewater treatment, cosmetics, and food science, among others ${ }^{2}$ and a large number of derivatives have been described. ${ }^{3}$ However, despite the numerous advantages and unique properties, its films are often brittle, which limits their applications. One way to improve the mechanical properties (and other functionalities) of chitosan films, is to prepare blends with other polymers. In the past few years, a considerable number of studies dealing with the blending of chitosan with various synthetic and natural polymers, such as poly(vinyl alcohol) ${ }^{4,5}$ poly ( $N$-vinyl pyrrolidone) ${ }^{6}$ poly(ethylene oxide), ${ }^{7}$ starch, ${ }^{5}$ collagen, ${ }^{8}$ water-soluble tertiary polyamides, ${ }^{9}$ cellulose ${ }^{10-13}$ and its derivatives, ${ }^{4,5}$ has been published.

Chitosan-cellulose blends are of particular interest $\mathrm{t}^{10-13}$ because of the structural similarity of these two biopolymers,

aDepartment of Chemistry and CICECO, Campus de Santiago,

University of Aveiro, 3810-193, Aveiro,Portugal.E-mail: cfreire@ua.pt; Fax: + 351234370 084; Tel: + 351234370604

${ }^{b}$ University of Pau and Adour Countries (UPPA), IPREM (UMR

CNRS 5254), Helioparc Pau Pyrenées-2, Avenue P. Angot, 64053,

Pau Cedex 09, France resulting in materials that combine the physicochemical properties of chitosan with the excellent mechanical properties of natural fibers. Several authors have studied the structure of these blends, obtained in solution ${ }^{10,11,13}$ or in the solid phase, ${ }^{14}$ and found evidence of interactions, mainly on the interfacial region between chitosan and cellulose. ${ }^{15}$

More recently, the incorporation of micro and nano-cellulose fibers, obtained by mechanical, enzymatic or chemical treatments, into several polymeric matrices, including chitosan, allowed obtaining materials with superior mechanical properties and transparency. ${ }^{16-18}$ The search for new renewable transparent films for electronic devices and also packaging applications is a very recent and promising research field. ${ }^{19-21}$

Bacterial cellulose, produced by Acetobacter xylinum, is becoming a promising biopolymer for several applications, including optically transparent nanocomposites, ${ }^{22-25}$ due to its unique properties, such as high mechanical strength, high crystallinity and a highly pure nanofibrillar network structure. However, to the best of our knowledge, the preparation and characterization of highly transparent chitosan-bacterial cellulose films has never been reported. The published studies deal only with the preparation of chitosan-bacterial cellulose mixed materials through $(i)$ the modification of the bacterial cellulose biosynthesis conditions, by the addition of polyaminosaccharide modifiers into the culture medium ${ }^{26,27}$ and (ii) dipping a dried bacterial cellulose membrane into an acetic acid solution of chitosan. ${ }^{28}$ The resulting membranes were characterized and showed valuable features including superior mechanical properties in a wet and a dry state, a high water absorption capacity, a high average surface area, high moisture-keeping properties as well as bacteriostatic and bactericidal activity. ${ }^{27,28}$

In the present paper, we describe the preparation and characterization of new transparent nanocomposite films based on different chitosan matrices and bacterial cellulose nanoand micro-fibrils as reinforcing agents. Two chitosan samples, with distinct molecular weights and thus originating solutions with different viscosities, were used, with the aim of preparing 
nanocomposites with different bacterial cellulose contents. In addition, a water soluble chitosan was also used in order to avoid the use of acetic acid solutions and because these derivatives displayed enhanced antimicrobial properties. ${ }^{29}$

These new materials were obtained through a simple and fully green approach by casting a water-based suspension of chitosan and bacterial cellulose nanofibrils.

\section{Experimental}

\section{Materials}

Two different chitosans $(\mathrm{CH})$ were used in this work, a relatively low molecular weight sample ( $\mathrm{LCH})$, kindly provided by Norwegian Chitosan AS (Norway), and a high molecular weight $(\mathrm{HCH})$ one, purchased from Mahtani Chitosan PVT.Ltd. (India). These commercial samples were purified by dissolution in a $1 \%(\mathrm{v} / \mathrm{v})$ aqueous $\mathrm{CH}_{3} \mathrm{CO}_{2} \mathrm{H}$ solution, filtered and precipitated by neutralizing with $\mathrm{NaOH}$ up to a $\mathrm{pH}$ of 8.5 . The ensuing precipitates were washed with distilled water until a neutral $\mathrm{pH}$ and air dried. Their viscosity-average molar mass, obtained at $25{ }^{\circ} \mathrm{C}$ from a $0.3 \mathrm{M} \mathrm{CH}_{3} \mathrm{CO}_{2} \mathrm{H} / 0.2 \mathrm{M} \mathrm{CH}_{3} \mathrm{CO}_{2} \mathrm{Na}$ solution, using the published Mark-Houwink constants, ${ }^{30}$ were $90000 \mathrm{~g} / \mathrm{mol}$ for $\mathrm{LCH}$ and $350000 \mathrm{~g} / \mathrm{mol}$ for $\mathrm{HCH}$. The degrees of deacetylation (DDA), determined by ${ }^{1} \mathrm{H}$ NMR (in $\mathrm{D}_{2} \mathrm{O}$ containing $1 \%$ of $\mathrm{CD}_{3} \mathrm{COOD}$ ) using a DRX-300 Brüker spectrometer, were found to be 90 and $97 \%$ for $\mathrm{LCH}$ and $\mathrm{HCH}$, respectively. ${ }^{31}$

In order to synthesize a water soluble quaternary ammonium derivative of chitosan (Fig. 1), following the procedure described by Seong et al. ${ }^{29} 5.0 \mathrm{~g}$ of purified chitosan $(\mathrm{HCH})$ were dissolved in $250 \mathrm{ml}$ of an aqueous solution of $1 \%$ acetic acid; glycidyltrimethylammonium chloride (GTMAC-purchased from Fluka, 90\% purity), with a GTMAC/HCH molar proportion of $4 / 1$, was added with stirring. This mixture was kept at $65^{\circ} \mathrm{C}$ for $24 \mathrm{~h}$ under a $\mathrm{N}_{2}$ atmosphere. The ensuing water soluble chitosan (WSHCH) derivative was precipitated and washed with ethanol (purchased from Sigma-Aldrich, 90\% purity). The substitution degree of the amino groups was around $30 \%$, as determined by ${ }^{1} \mathrm{H}$ NMR spectroscopy following a previously described method. ${ }^{31}$

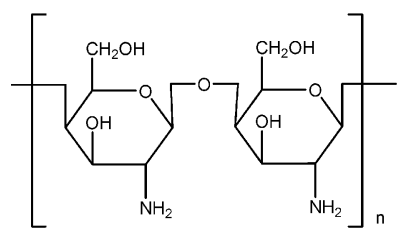

a)

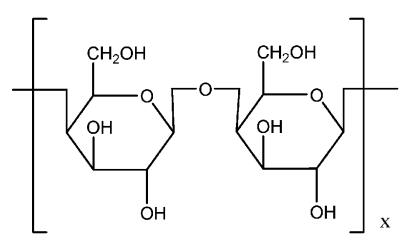

c)

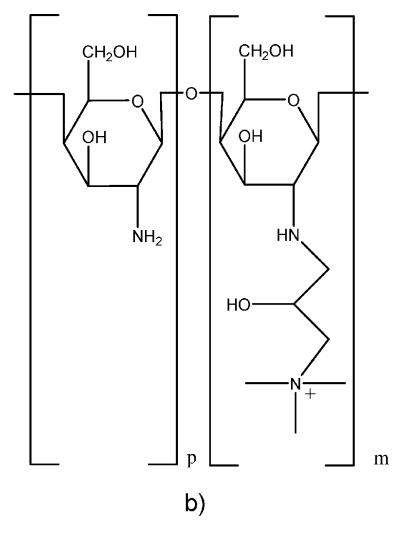

b)
Bacterial cellulose (BC) (tridimensional network of nanoand microfibrils with 10-200 nm width) in the shredded wet form ( $95 \%$ humidity), was supplied by Forschungszentrum für Medizintechnik und Biotechnologie e.V. (Germany).

\section{Chitosan/bacterial cellulose nanocomposite films preparation}

For the preparation of the $\mathrm{HCH}, \mathrm{LCH}$ and WSHCH nanocomposite films, $1.5 \%$ solutions were first prepared, by dissolving the corresponding powdered chitosan samples in aqueous acetic acid $(1 \% \mathrm{v} / \mathrm{v})$ or in water (in the case of WSHCH). Different amounts of bacterial cellulose were added to these solutions in order to obtain films with BC contents of 5 and $10 \%$ for the $\mathrm{HCH}$ and WSHCH films and 5, 10, 30 and $40 \%$ for the $\mathrm{LCH}$ films, with respect to the dry weight of chitosan (the maximum amount of BC used with each type of chitosan was limited by the final high viscosity of the ensuing mixtures as, above these maximum values, they could not be processed under the reported conditions). Then, BC was dispersed in the solutions and homogenized using an Ultra-Turrax equipment during 45 minutes (20500 rpm), filtered to remove impurities and degassed to remove entrapped air. Both unfilled $\mathrm{CH}$ and nanocomposite films based on chitosan and bacterial cellulose (CHBC films) were then prepared by casting at $30{ }^{\circ} \mathrm{C}$ in a ventilated oven for $16 \mathrm{~h}$, using an acrylic plate $\left(10 \times 10 \mathrm{~cm}^{2}\right)$ as the mould. The identification of all samples studied is summarised in Table 1.

Before characterization, all films were kept in a conditioning cabinet at $50 \%$ relative humidity $(\mathrm{RH})$ and $25^{\circ} \mathrm{C}$ to ensure the stabilization of their water content.

\section{Films characterization}

The $\mathrm{CH}$ and $\mathrm{CHBC}$ films were characterized using scanning electron microscopy (SEM), atomic force microscopy (AFM), $\mathrm{X}$-ray diffraction (XRD), transmittance (visible light), thermogravimetry (TGA) and tensile tests.

SEM micrographs of the film surfaces were obtained on a HR-FESEM SU-70 Hitachi equipment operating at $1.5 \mathrm{kV}$ and that of BC was taken with a Hitachi S4100 equipment operating in the field emission mode.

AFM measurements were performed on an Innova AFM Veeco Instrument. The images were scanned in a tapping

Table 1 Identification of the $\mathrm{CH}$-based films

\begin{tabular}{llc}
\hline Sample & CH sample & $\%$ of $\mathrm{BC}^{a}$ \\
\hline HCH & High molecular weight & - \\
HCHBC5\% & High molecular weight & 5 \\
HCHBC10\% & High molecular weight & 10 \\
LCH & Low molecular weight & - \\
LCHBC5\% & Low molecular weight & 5 \\
LCHBC10\% & Low molecular weight & 10 \\
LCHBC30\% & Low molecular weight & 30 \\
LCHBC40\% & Low molecular weight & 40 \\
WSHCH & High molecular weight & - \\
(water soluble derivative) & \\
WSHCHBC5\% & $\begin{array}{l}\text { High molecular weight } \\
\text { (water soluble derivative) }\end{array}$ & 5 \\
WSHCHBC10\% & $\begin{array}{l}\text { High molecular weight } \\
\text { (water soluble derivative) }\end{array}$ & 10
\end{tabular}

${ }^{a}$ In relation to the oven dry chitosan mass.

Fig. 1 Chemical structures of (a) chitosan, (b) its water solublederivative and (c) cellulose. 
mode under ambient conditions using rectangular silicon cantilevers from veeco-probes (MMP-12100-10), resonating at about $110 \mathrm{kHz}$.

The X-ray diffraction (XRD) measurements were carried out with a Philips X'pert MPD diffractometer using $\mathrm{Cu} \mathrm{K} \alpha$ radiation.

The transmittance spectra of the $\mathrm{CH}$ films and CHBC films were measured with a UV-vis Spectrophotometer (Perkin-Elmer UV 850) equipped with a $15 \mathrm{~cm}$ diameter integrating sphere bearing the holder in the horizontal position. Spectra were recorded at room temperature in steps of $1 \mathrm{~nm}$, in the range $400-700 \mathrm{~nm}$.

TGA assays were carried out with a Shimadzu TGA 50 analyzer equipped with a platinum cell. Samples were heated at a constant rate of $10{ }^{\circ} \mathrm{C} / \mathrm{min}$ from room temperature to $800{ }^{\circ} \mathrm{C}$ under a nitrogen flow of $20 \mathrm{~mL} / \mathrm{min}$. The thermal decomposition temperature was taken as the onset of significant $(\sim 0.5 \%)$ weight loss, after the initial moisture loss.

Tensile tests were performed in room conditions on a TAHdi Stable Micro Systems Texture Analyser using a load cell of $5 \mathrm{~kg}$ and operating at a deformation rate of $0.5 \mathrm{~mm} / \mathrm{s}$. Tensile strength, tensile modulus, and elongation to break were calculated using the Instron Series IX software.

\section{Results and discussion}

\section{Morphology}

A selection of SEM micrographs of the surface of LCHBC films filled with $5 \%, 10 \%$ and $40 \%$ of $\mathrm{BC}$ and of WSHCH film filled with 5\% of BC is shown in Fig. 2. The characteristic tridimensional fibrillar network of $\mathrm{BC}$ was clearly observed on the surface of the films. The SEM micrographs also provided evidence of the good dispersion of the BC fibrils on the matrices, without noticeable aggregates, even for high reinforcement contents.

The surface of the films was also inspected by AFM (Fig. 3). The surface of the unfilled $\mathrm{CH}$ films displayed a typical granular morphology (around 100-300 nm), ${ }^{32}$ while that of the CHBC nanocomposite films consisted mainly of randomly assembled nanofibrils (10-200 nm) of $\mathrm{BC}$ and $\mathrm{CH}$ granules.

\section{X-Ray diffraction}

The X-ray diffraction patterns of unfilled $\mathrm{CH}$ films, $\mathrm{BC}$ and CHBC nanocomposite films are shown in Fig. 4 and 5. Both $\mathrm{HCH}$ and $\mathrm{LCH}$ showed the typical X-ray diffraction pattern of chitosan substrates with strong peaks at around $2 \theta 12$ and $19^{\circ} .{ }^{33}$ However, the $\mathrm{HCH}$ film was much more crystalline than the LCH counterpart (Fig. 4). The chemical modification of $\mathrm{HCH}$ with glycidyltrimethylammonium chloride led to an extensive decline of the crystallinity, since the WSHCH film displayed a diffraction pattern typical of a predominantly amorphous material, as previously observed with other watersoluble chitosan derivatives. ${ }^{34} \mathrm{BC}$ exhibited a diffractogram typical of Cellulose I (native cellulose), with the main peaks at $2 \theta 14.3,15.9,22.6$ and $33.7^{\circ}$ (Fig. 4 ). ${ }^{35}$

The X-ray diffractograms of all CHBC nanocomposite films showed typical diffraction peaks of both polysaccharide components (Fig. 5). The incorporation of BC seemed also to

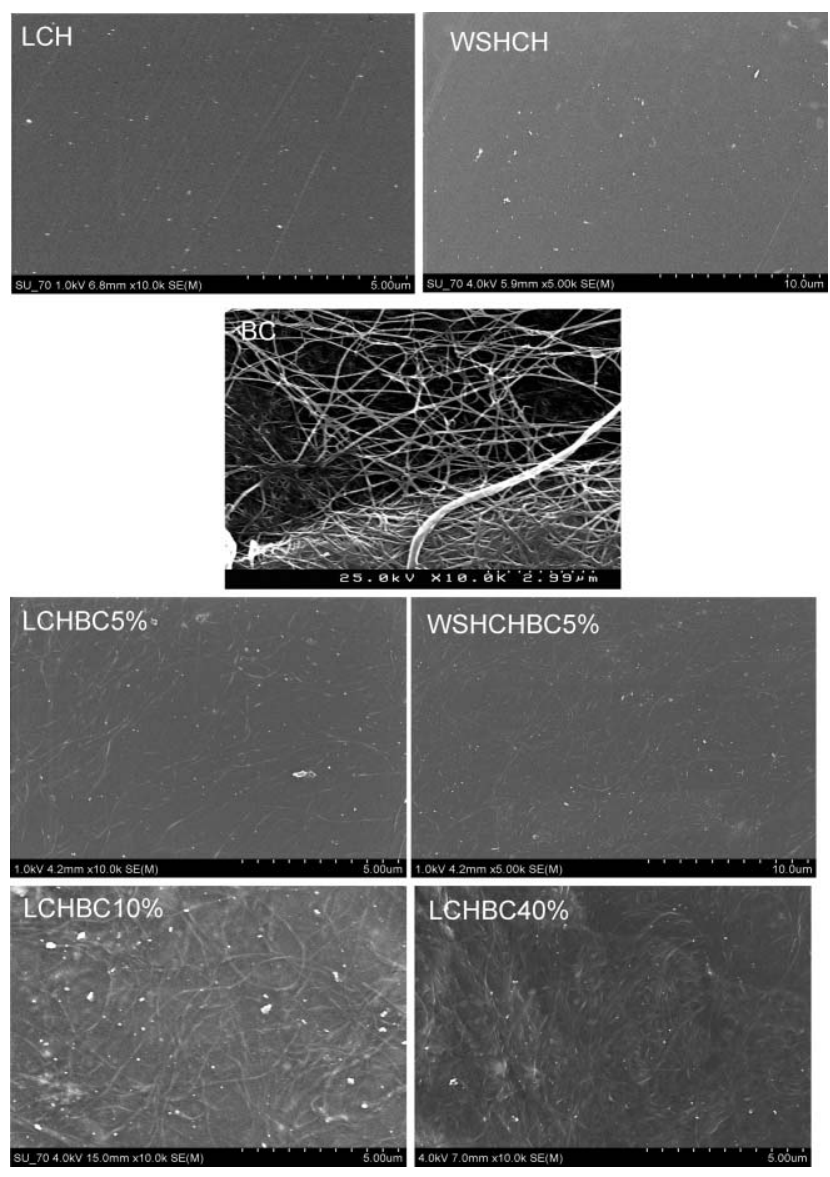

Fig. 2 SEM micrographs of LCH and WSHCH films, BC and the surface of LCH films filled with $5 \%, 10 \% 40 \%$ of $\mathrm{BC}$ and of $\mathrm{WSHCH}$ film filled with $5 \%$ of BC.

promote the crystallinization of chitosan chains, since the peaks at $2 \theta 12$ and $19^{\circ}$ appear in the diffractogram of WSHCHBC films (Fig. 5). This phenomenon is probably explained by the organized deposition of chitosan chains on the surface of the crystalline domains of bacterial cellulose nanofibrils.

\section{Optical properties}

The transmittance of the $\mathrm{CH}$ and $\mathrm{CHBC}$ films (approximately $30 \mu \mathrm{m}$ thick) is shown in Fig. 6. The transmittance in the range of $400-700 \mathrm{~nm}$ was about $90 \%$ for $\mathrm{HCH}$ and WSHCH chitosan films and about $80 \%$ for the LCH film. This difference was probably related to the light-brownish colour of the pristine $\mathrm{LCH}$ sample due to the natural occurrence of trace amounts of coloured impurities in some chitosan samples, which however could be removed, if required, using adequate purification procedures. ${ }^{2}$ The transmittance values reported here are in good agreement with published transmittance data for chitosan substrates. ${ }^{36}$

In all cases, the transmittance of $\mathrm{CH}$ films was not affected by the incorporation of $5 \%$ of $\mathrm{BC}$ nanofibrils. However, for $\mathrm{BC}$ contents equal to or higher than $10 \%$, the transmittance decreased to $80 \%$ and $70 \%$, respectively, for $\mathrm{HCH} / \mathrm{WSHCH}$ and LCH composite films. The high transparency of these new nanocomposites is also evidenced by the pictures showed in Fig. 7. 


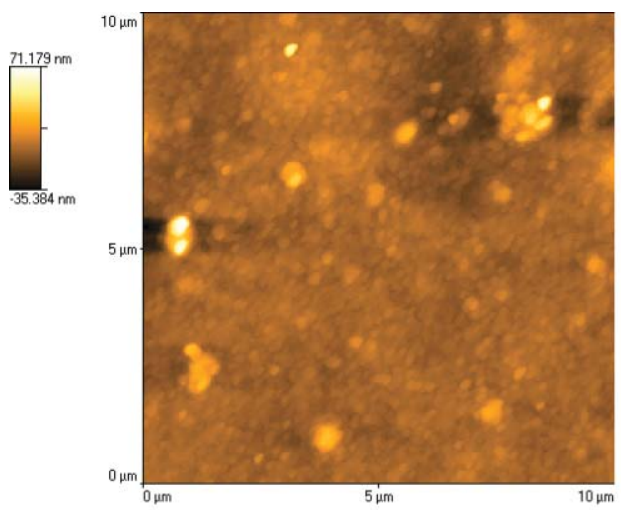

a)

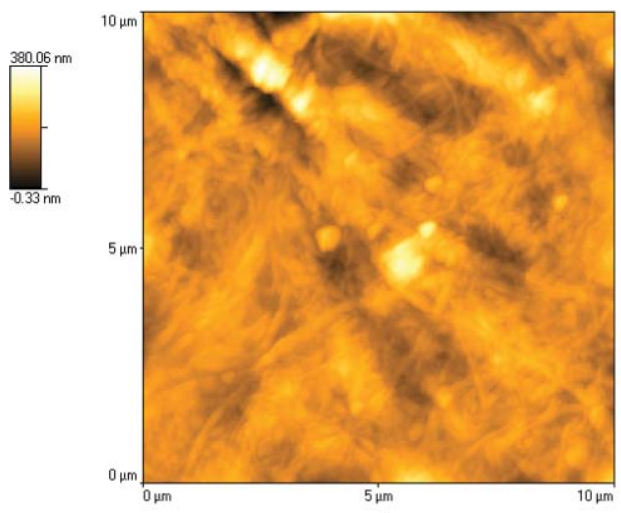

c)

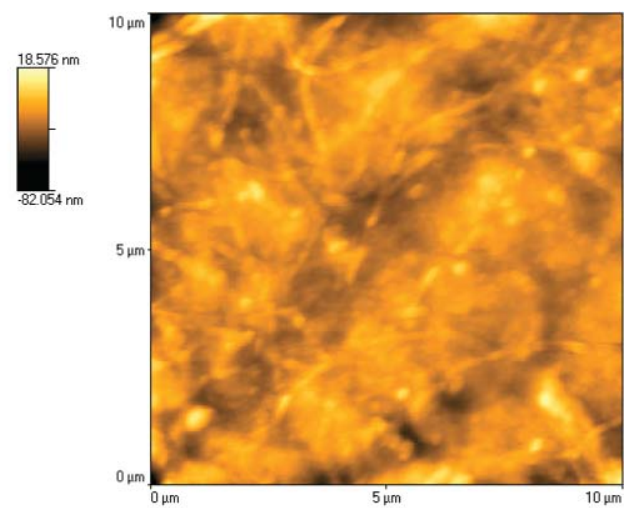

b)

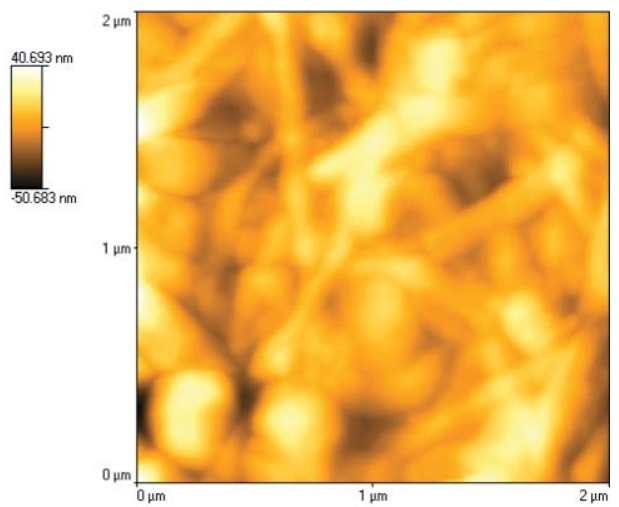

d)

Fig. 3 AFM (tapping mode) topographic images of the surface of a LCH film (a) and of LCHBC nanocomposite films with $10 \%$ (b) and $40 \%$ (c and $\mathrm{d}$, at two different magnifications) of $\mathrm{BC}$.

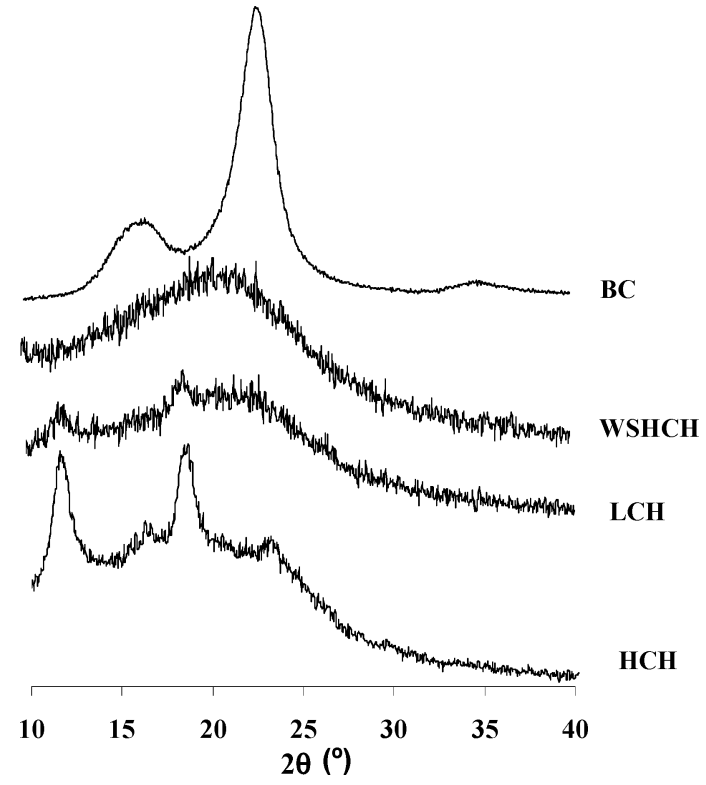

Fig. 4 X-Ray diffractograms of $\mathrm{BC}$ and $\mathrm{CH}$ samples $(\mathrm{HCH}, \mathrm{LCH}$ and $\mathrm{HWSCH}$ ).

\section{Thermal properties}

Thermogravimetric analysis of $\mathrm{CH}$-based films was carried out to evaluate their degradation profiles and thermal stability
(Fig. 8, Table 2). In the thermograms of $\mathrm{HCH}$ (Fig. 8a) and $\mathrm{LCH}$ (not shown), the two mass losses, at around $100{ }^{\circ} \mathrm{C}$ and $200^{\circ} \mathrm{C}$, were associated with the volatilization of water and acetic acid, respectively, and the maximum degradation step at $300^{\circ} \mathrm{C}$ was assigned to the degradation of chitosan. ${ }^{37}$ The WSHCH (Fig. 8a) was more unstable than the unmodified $\mathrm{CH}$, since it started to decompose at around $180^{\circ} \mathrm{C}$ with the maximum step at $270{ }^{\circ} \mathrm{C}$. Moreover, in this case the loss of acetic acid was not observed because the films were casted from pure water.

BC showed a typical main double weight-loss feature, with a maximum decomposition temperature in the range of 353-370 ${ }^{\circ} \mathrm{C}$ (Fig. 8a). ${ }^{38}$ The mass loss at around $100{ }^{\circ} \mathrm{C}$, associated with the volatilization of water was also observed in this case.

In general, the TGA tracings of the CHBC nanocomposites were a combination of those of $\mathrm{CH}$ and $\mathrm{BC}$. The addition of $\mathrm{BC}$ to the $\mathrm{CH}$ matrices resulted, in most cases, in a slight increase in the thermal stability of the films, as exemplified in Fig. $8 \mathrm{~b}$ for the WSHCHBC5\%. The relevant thermal data $\left(T \mathrm{~d}_{\mathrm{i}}, T \mathrm{~d}_{1}\right.$ and $\left.T \mathrm{~d}_{2}\right)$ are shown in Table 2.

\section{Mechanical properties}

The effect of the BC content, chitosan DP and quaternization on the large strain behaviour of CHBC composite films was studied up to their failure. The Young modulus, tensile strength and elongation at break, determined from the typical stress-strain curves, are displayed in Fig. 9(a-c). 
(A)

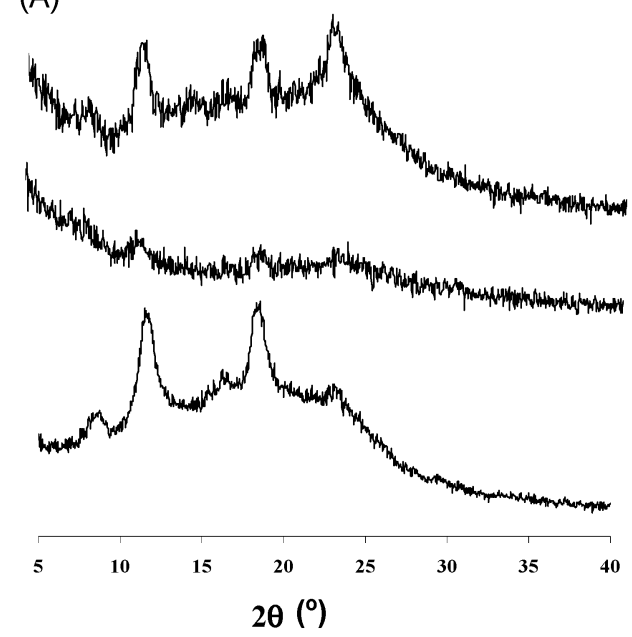

(B)
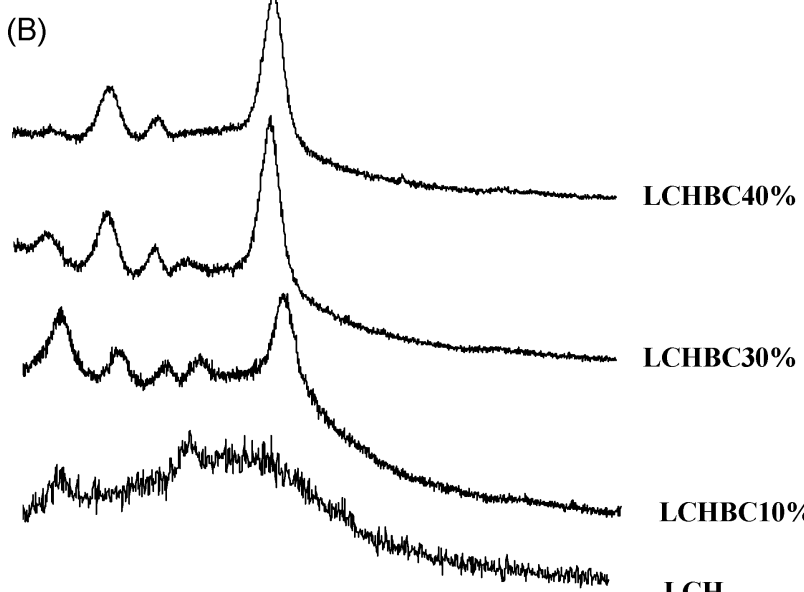

$\begin{array}{lllllll}10 & 15 & 20 & 25 & 30 & 35 & 40\end{array}$ $2 \theta\left({ }^{\circ}\right)$

(C)

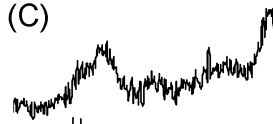

whent"

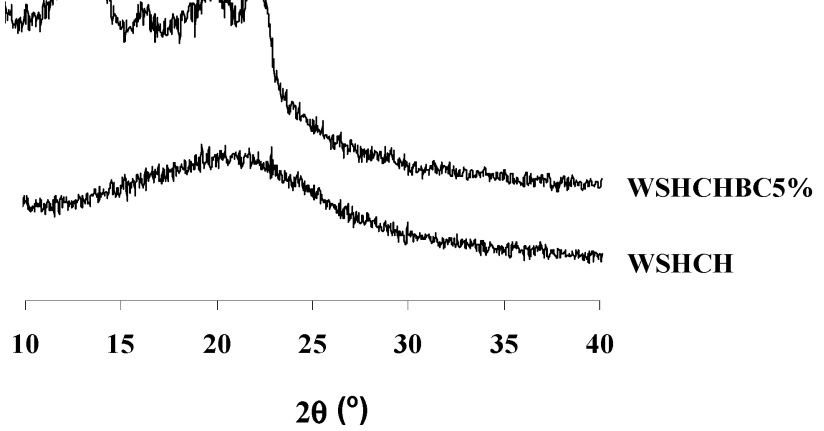

Fig. 5 X-Ray diffractogram of CHBC nanocomposite films.

As expected, $\mathrm{HCH}$ displayed a higher Young modulus than that of LCH. ${ }^{39}$ WSHCH displayed the lowest modulus, confirming that this functionalization clearly affected the mechanical
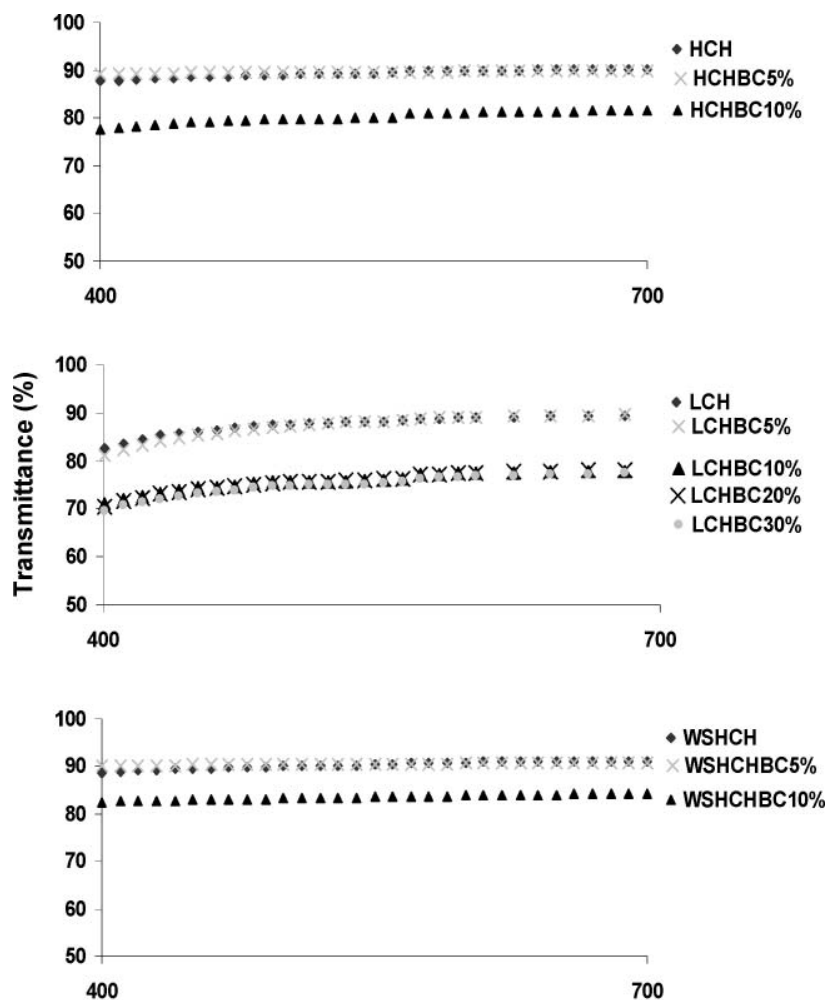

Wavelength $(\mathrm{nm})$

Fig. 6 Transmittance of unfilled $\mathrm{CH}$ films and some corresponding CHBC nanocomposite films with different BC contents.

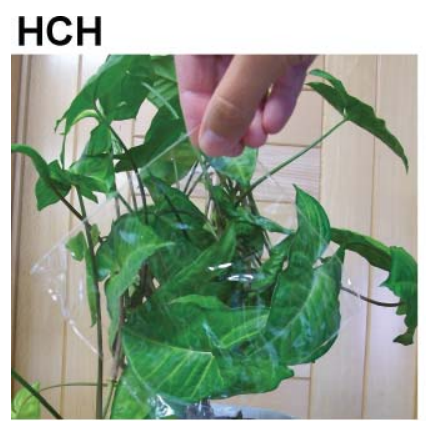

\section{$\mathrm{LCH}$}
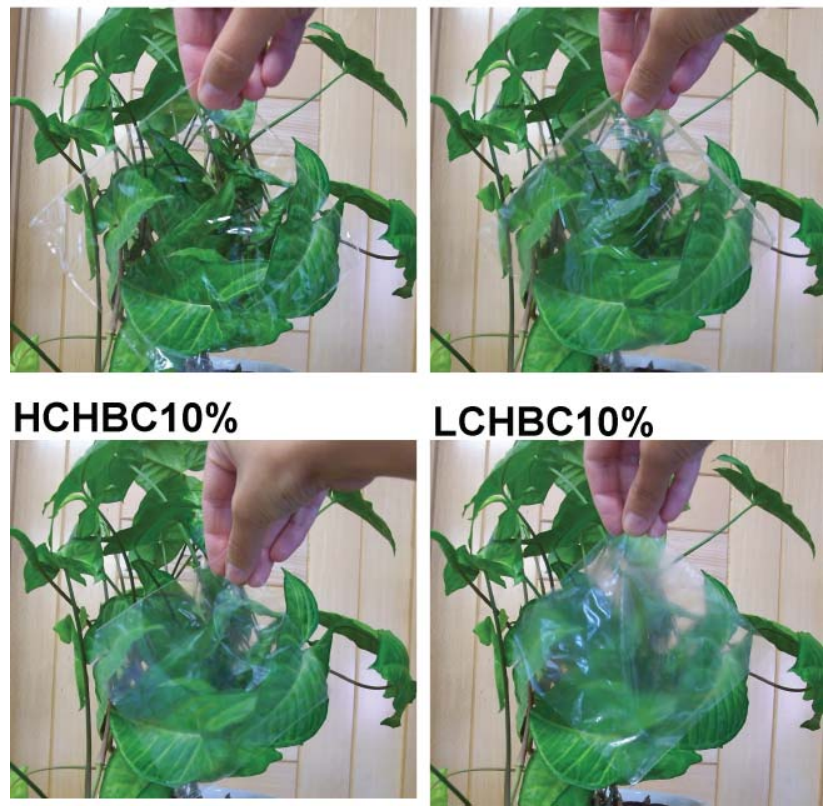

Fig. 7 Images of $\mathrm{CH}$ and $\mathrm{CHBC}$ nanocomposite films placed in front of a green plant.

behavior of chitosan substrates, associated with the drastic decrease of crystallinity observed by X-ray diffraction.

The Young modulus of the CHBC composite films increased considerably with the BC content (Fig. 9a). At a fiber content of $10 \%$, the Young Modulus was 40, 32 and $114 \%$ higher than 
Table 2 Thermal data of the studied samples obtained from the TGA plots

\begin{tabular}{llll}
\hline Sample & $T \mathrm{~d}_{\mathrm{i}}\left({ }^{\circ} \mathrm{C}\right)$ & $T \mathrm{~d}_{1}\left({ }^{\circ} \mathrm{C}\right)$ & $T \mathrm{~d}_{2}\left({ }^{\circ} \mathrm{C}\right)$ \\
\hline LCH & 237 & $304(60)^{a}$ & \\
LCHBC5\% & 237 & $302(60)$ & $370(40)$ \\
LCHBC10\% & 237 & $304(59)$ & $370(40)$ \\
LCHBC30\% & 239 & $300(66)$ & $379(56)$ \\
LCHBC40\% & 239 & $301(65)$ & $379(55)$ \\
HCH & 229 & $306(60)$ & $-{ }^{b}$ \\
HCHBC5\% & 225 & $294(62)$ & $-{ }^{b}$ \\
HCHBC10\% & 226 & $260(65)$ & $-{ }^{b}$ \\
WSHCH & 186 & $270(69)$ & $-{ }^{b}$ \\
WSHCHBC5\% & 231 & $280(72)$ & $-{ }^{b}$ \\
WSHCHBC 10\% & 230 & $276(73)$ &
\end{tabular}

${ }^{a}$ Number in parentheses refer to the percentage of residual quantity of materials attained at $T \mathrm{~d}_{1}$ and $T \mathrm{~d}_{2} \cdot{ }^{b} T \mathrm{~d}_{2}$ is overlapped with $T \mathrm{~d}_{1}$ as shown in Fig. 8b for WSCH derivatives
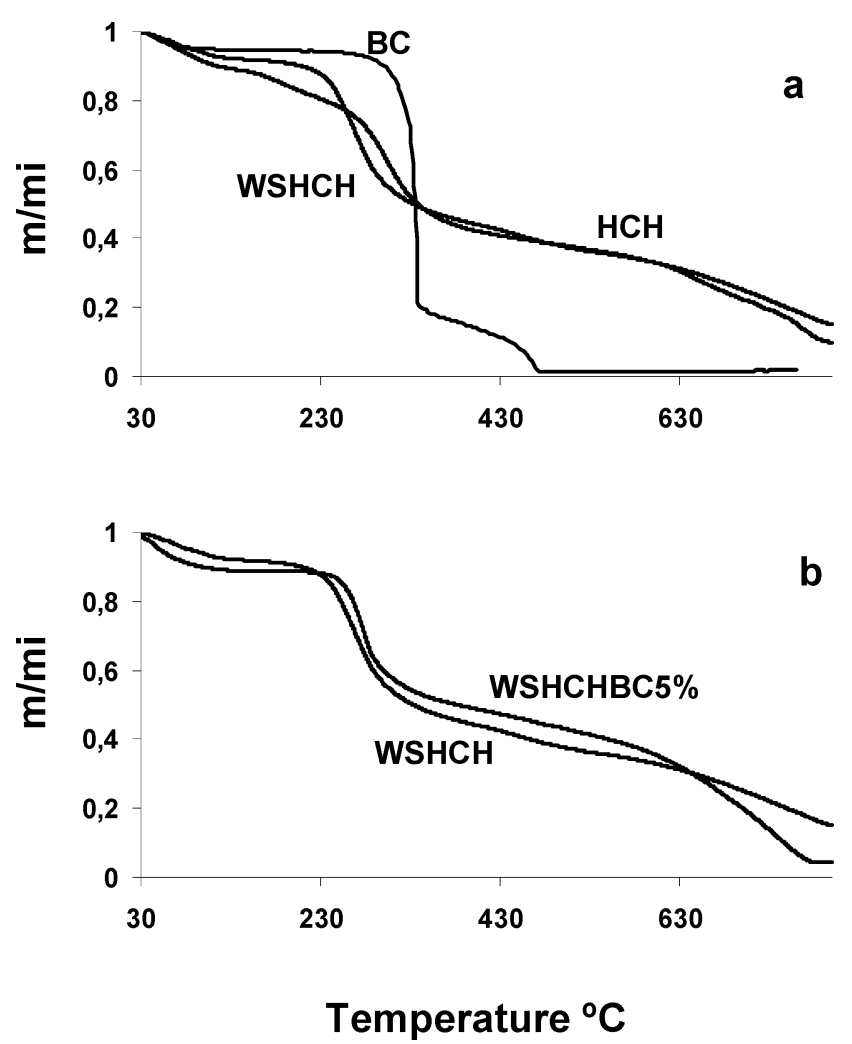

Fig. 8 Thermogravimetric curves for $\mathrm{BC}, \mathrm{HCH}, \mathrm{WSHCH}$ (a) and WSHCHBC $5 \%$ (b).

that of the unfilled $\mathrm{CH}$ substrates for the HCHBC, LCHBC and WSHCHBC nanocomposite films, respectively. The increment was particularly relevant for the WSHCHBC films, which can be related to the above mentioned increase in crystallinity of this mainly amorphous matrix after incorporation of the $\mathrm{BC}$ nanofibrils. Moreover, the LCHBC films with higher BC contents (30 and 40\%) presented similar Young moduli to those of $\mathrm{HCHBC}$ and WSHCHBC films with only $10 \%$ of cellulose nanofibrils. These results indicated that the $\mathrm{HCH}$ and the $\mathrm{WSHCH}$ matrices are better for the preparation of transparent nanocomposite films with higher mechanical properties.

The incorporation of $\mathrm{BC}$ also promoted a considerable increase in the stress of the nanocomposite films (Fig. 9b).

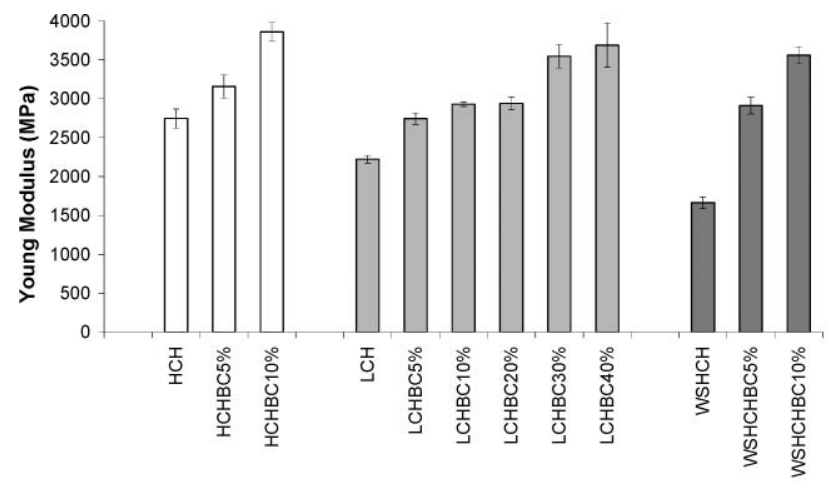

a)

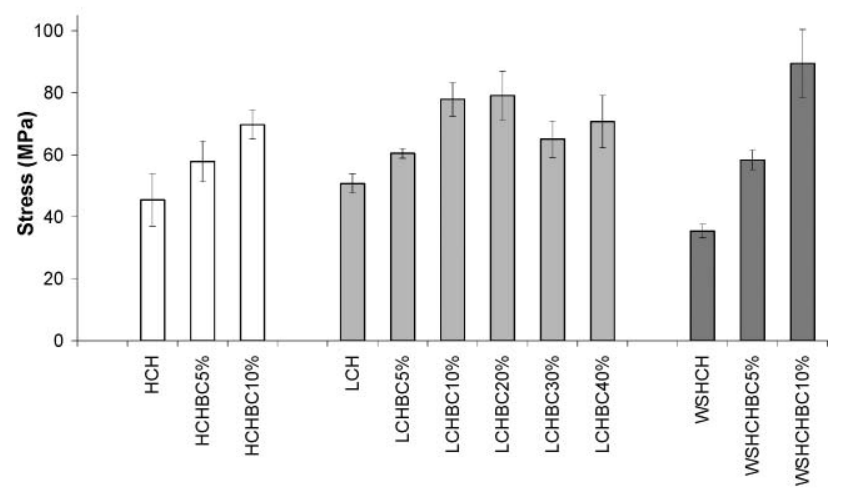

b)

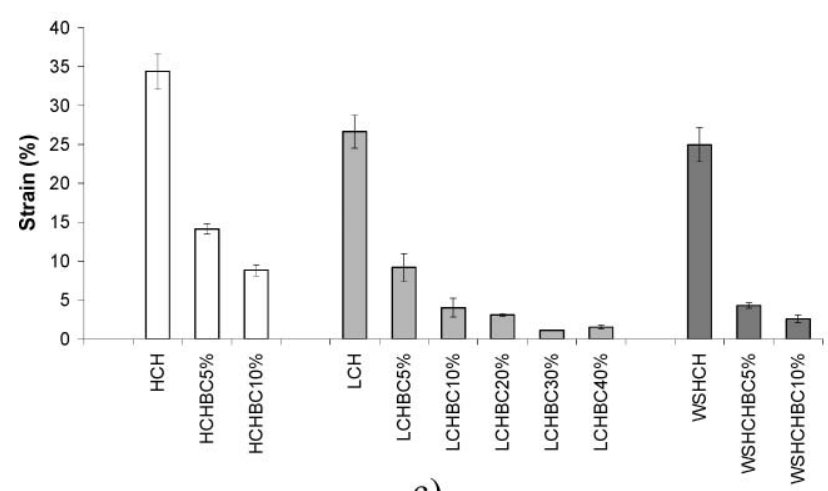

c)

Fig. 9 Young modulus, tensile strength and elongation to break of $\mathrm{CH}$ samples and corresponding nanocomposite films with different $\mathrm{BC}$ contents.

Additionally, the presence of BC caused a significant decrease in the elongation at break (Fig. 9c), which was more pronounced for higher cellulose contents.

The superior mechanical properties of all CHBC films compared with those of the unfilled $\mathrm{CH}$ films, confirmed the good interfacial adhesion and the strong interactions between the two components. These results can be explained by the inherent morphology of BC with its nanofibrillar network and the similar structures of the two polysaccharides. In fact, huge increments in the mechanical performance of several composite materials have previously been reported by the incorporation of BC nanofibers (or other nanocellulose substrate) in other kind of matrices, such as phenolic resins. ${ }^{40}$ 


\section{Conclusion}

New chitosan-bacterial cellulose nanocomposite films were prepared by a simple and green procedure based on casting water (or $1 \%$ acetic solutions) suspensions of chitosan with different contents of bacterial cellulose. These obtained materials are transparent, flexible and present significantly better mechanical properties than the corresponding unfilled chitosan films. They also have a reasonable thermal stability and low $\mathrm{O}_{2}$ permeability (preliminary results). Their notable properties are promising for applications in transparent biodegradable and anti-bacterial packaging, medical and electronic devices.

\section{Acknowledgements}

The authors thank Norwegian Chitosan AS. (Norway) for their generous gift of chitosan ( $\mathrm{LCH})$. The authors acknowledge Laurent Rubatat and Sylvie Blanc (IPREM, Pau, France) for their contribution on AFM and spectroscopy experiments. The authors are also grateful to Márcia Neves and Ricardo Pinto (CICECO, University of Aveiro, Portugal) for performing XRD and SEM experiments. Susana Fernandes and Lúcia Oliveira thank the Fundação para a Ciência e a Tecnologia (Portugal) for Scientific Research grants (SFRH/BD/41388/ 2007, SFRH/BPD/38515/2007, respectively).

\section{References}

1 A. Gandini, and M. N. Belgacem, in Monomers, Polymers and Composites from Renewable Resources, ed. M. N. Belgacem and A. Gandini, Elsevier, London, 2008, 1-16.

2 C. Peniche, W. Argüelles-Monal, and F. M. Goycoolea, in Monomers, Polymers and Composites from Renewable Resources, ed. M. N. Belgacem and A. Gandini, Elsevier, London, 2008, 517-542.

3 V. K. Mourya and N. N. Inamdar, React. Funct. Polym., 2008, 68, 1013-1051.

4 M. Mucha and A. Pawlak, Thermochim. Acta, 2005, 427, 6976

5 A. Pawlak, and A. Mucha, in 29th Conference of the North American Thermal Analysis Society, Elsevier Science Bv, St Louis, Michigan, 2001, 153-166.

6 K. Sakurai, T. Maegawa and T. Takahashi, Polymer, 2000, 41, 70517056.

7 M. M. Amiji, Biomaterials, 1995, 16, 593-599.

8 A. Sionkowska, M. Wisniewski, J. Skopinska, C. J. Kennedy and T. J. Wess, J. Photochem. Photobiol., A, 2004, 162, 545-554.

9 L. Fang and S. H. Goh, J. Appl. Polym. Sci., 2000, 76, 17851790.

10 Y. K. Twu, H. I. Huang, S. Y. Chang and S. L. Wang, Carbohydr. Polym., 2003, 54, 425-430.
11 Y. B. Wu, S. H. Yu, F. L. Mi, C. W. Wu, S. S. Shyu, C. K. Peng and A. C. Chao, Carbohydr. Polym., 2004, 57, 435-440.

12 S. Z. Rogovina and G. A. Vikhoreva, Glycoconjugate J., 2006, 23, 611-618.

13 M. Hasegawa, A. Isogai, F. Onabe, M. Usuda and R. H. Atalla, J. Appl. Polym. Sci., 1992, 45, 1873-1879.

14 S. Z. Rogovina, T. A. Akopova, G. A. Vikhoreva, S. N. Zelenetskii, I. N. Gorbacheva and N. V. Suslova, Polym. Sci. Ser. B, 2001, 43, 265-268.

15 J. M. Urreaga and M. U. de la Orden, Eur. Polym. J., 2006, 42, 2606-2616.

16 D. Nordqvist, J. Idermark and M. S. Hedenqvist, Biomacromolecules, 2007, 8, 2398-2403.

17 Y. Kim, R. Jung, H. S. Kim and H. J. Jin, Curr. Appl. Phys., 2009, 9, S69-S71.

18 H. Fukuzumi, T. Saito, T. Wata, Y. Kumamoto and A. Isogai, Biomacromolecules, 2009, 10, 162-165.

19 R. Jung, H. S. Kim, Y. Kim, S. M. Kwon, H. S. Lee and H. J. In, J. Polym. Sci., Part B: Polym. Phys., 2008, 46, 1235-1242.

20 Y. Shimazaki, Y. Miyazaki, Y. Takezawa, M. Nogi, K. Abe, S. Ifuku and H. Yano, Biomacromolecules, 2007, 8, 2976-2978.

21 M. Nogi, S. Iwamoto, A. N. Nakagaito and H. Yano, Adv. Mater., 2009, 21, 1595-1598.

22 S. Ifuku, M. Nogi, K. Abe, K. Handa, F. Nakatsubo and H. Yano, Biomacromolecules, 2007, 8, 1973-1978.

23 M. Nogi, K. Handa, A. N. Nakagaito and H. Yano, Appl. Phys. Lett., 2005, 87, 243110.

24 M. Nogi, S. Ifuku, K. Abe, K. Handa, A. N. Nakagaito and H. Yano, Appl. Phys. Lett., 2006, 88, 133124.

25 M. Nogi and H. Yano, Adv. Mater., 2008, 20, 1849-1852.

26 D. Ciechanska, Fibres Text. East. Eur., 2004, 12, 69-72.

27 M. Phisalaphong and N. Jatupaiboon, Carbohydr. Polym., 2008, 74, 482-488.

28 V. Dubey, L. K. Pandey and C. Saxena, J. Membr. Sci., 2005, 251, 131-136.

29 H. S. Seong, H. S. Whang and S. W. Ko, J. Appl. Polym. Sci., 2000, 76, 2009-2015.

30 M. Rinaudo, M. Milas and L. P. Dung, Int. J. Biol. Macromol., 1993 15, 281-285.

31 J. Desbriéres, C. Martinez and M. Rinaudo, Int. J. Biol. Macromol., 1996, 19, 21-28.

32 Z. Zheng, L. Zhang, L. Kong, A. Wang, Y. Gong and X. Zhang, J. Biomed. Mater. Res., Part A, 2009, 89a, 453-465.

33 R. J. Samuels, J. Polym. Sci., Part B: Polym. Phys., 1981, 19, 10811105.

34 G. Ma, D. Yang, Y. Zhou, M. Xiao, J. F. Kennedy and J. Nie, Carbohydr. Polym., 2008, 74, 121-126.

35 D. N.-S. Hon, Chemical Modification of Lignocellulosic Materials, Marcell Dekker, New York, 1996.

36 A. Larena and D. A. Caceres, Appl. Surf. Sci., 2004, 238, 273-277.

37 M. J. Zohuriaan and F. Shokrolahi, Polym. Test., 2004, 23, 575-579.

38 D. Klemm, B. Philipp, T. Heinze, U. Heinze, and W. Wagenknecht, Comprehensive Cellulose Chemistry, vol. 1, Wiley-VCH, Weinheim, 1998.

39 R. H. Chen and H. D. Hwa, Carbohydr. Polym., 1996, 29, 353-358.

40 A. N. Nakagaito, S. Iwamoto and H. Yano, Appl. Phys. A: Mater. Sci. Process., 2005, 80, 93-97. 